\title{
Research on the Optimal Path of Enterprise Green Technology Innovation
}

\author{
Zhiyu $\mathrm{Li}^{1}$, Pengjuan $\mathrm{Lv}^{2 *}$, Shuai Hong ${ }^{3}$ \\ ${ }^{1}$ Institute of Economics study, Hebei University of Economics and Business, Shijiazhuang 050061; \\ ${ }^{2}$ Accounting School, Hebei University of Economics and Business, shijiazhuang,050061; \\ ${ }^{3}$ Collaborative Innovation Center for Beijing-Tianjin-Hebei Integrated Development, Hebei University of Economics and Business, \\ Shijiazhuang, 050061
}

\begin{abstract}
The construction of a green technology innovation system should not only give attention to technological innovation, but also pay attention to the heterogeneity of the enterprise itself. Therefore, from the dual perspectives of environmental regulation and corporate heterogeneity, we analyze the impact of corporate green technology innovation and believe that building a market-oriented green technology innovation system requires improving green development efficiency, promoting green technology R\&D and application, and strengthening the combination of policy tools. Thus to support green transformation and development.
\end{abstract}

\section{Introduction}

Since the 21 st century, environmental issues have been the subject of world attention, and the realization of regional sustainable development has become the consensus of the international community. China's economy is located in a critical period of transformation and upgrading, and environmental pollution and resource waste have increased the pressure for economic development. Although China's economy maintains rapid growth, climate deterioration and environmental pollution have seriously restricted the sustained and stable economic development. Many traditional enterprises have backward technology and extensive management, causing serious pollution of the atmosphere, soil, surface water, and groundwater. China's energy consumption in 2019 was 4.86 billion tons of standard coal, an increase of $34.6 \%$ over 2010; and the energy consumption per unit of GDP was 1.34 tons of standard coal per 10,000 yuan, still significantly higher than the level of developed countries in the world. Only by accelerating green progress can we effectively alleviate the problems of environmental pollution and resource depletion in economic progress and promote industrial enterprises to take the path of green development. The theory and practice of technological innovation at home and abroad show that market-oriented green technological innovation is more effective than technology-oriented innovation activities. Brown and D. Wield proposed the concept of green technology innovation as early as 1994. They believe that green technology innovation is driven by the realization of the coordinated development of economy, society and ecology, and integrates resource consumption, environmental pollution, and ecological indicators into all links of technological innovation, strive to meet the ecological needs of social progress, and promote coordinated economic and social development. (Cleff, 1999) noted that market demand and customer utility are important driving forces for companies to choose green technology innovation strategies. (Nasierowski, 2003) and others used the DEA method to evaluate the efficiency of green technology innovation and believed that the technological bias effect of environmental policies has become a trend based on "directed technological change" (DTC). (Hart, 2004) divides technology into green technology and nongreen technology. Built on the endogenous growth model, the influence of two technological innovations on economic growth is studied. (Roberto Roson, 2016) analyzes the economic effects of environmental changes and believes that policy designs that help to technological innovation can effectively improve green total factor productivity. (Paroussos, L, 2019) Research believes that reasonable financial policies and technological development have a positive impact on green development In the past, research on green technology innovation mostly analyzed external characteristics, and mainly used traditional input-output methods for performance analysis. There were comparatively few researches on the integration of elements to promote green innovation. The research on the optimization path of the green technology innovation system under the background of the marketoriented reform of elements has important functional significance for the construction of the market-oriented green technology system.

\footnotetext{
The first author: Zhiyu Li, man, assistant researcher, Hebei University of Economics and Business, Email: lizhiyu100@heuet.edu.cn, TELL 13426051541

Corresponding author: Pengjuan Lv Accounting School, Hebei University of Economics and Business, Email:

lvpengjuan@heuet.edu.cn
} 


\section{Impact factors of enterprise green technological innovation}

In the past green technology innovation system, the information was insufficient and opaque, the efficiency of resource allocation was low, and corporate green technology innovation motivation was insufficient, and the requirements for high-quality development were not truly implemented. The market-oriented reform of factors is mainly to achieve efficient allocation of factors by removing the obstacles to the free flow of factors. In the process of green technology innovation, the heterogeneity of policies, environment, and enterprises themselves have an important impact on the research and development and application of green technologies.

(1) Model construction

This article is based on the Solow growth model under

resource and environmental constraints, and incorporates resources and environment into the most basic Solow model. The expanded model includes the amount of green patent authorization, green capital investment, human capital, and environmental governance investment in each province, Industrial structure, energy consumption per unit of GDP 6 variables. In the time path under investigation, the real economic growth is correspondingly manifested as the result of the combined effect of green technology, capital, labor and other factors.

Because panel data can not only control the heterogeneity of sample individuals, but also have more information and greater representativeness, the classic panel data measurement model is used to empirically analyze the output efficiency of green technologies. Construct the following panel data measurement model to consider the impact of various factors on environmental economic growth. The model formula is shown below.

$$
\begin{gathered}
\ln E G R=C+\beta_{1} \ln G P+\beta_{2} \ln C L+\beta_{3} \ln L F+\beta_{4} \ln E R+\beta_{5} \ln I S+\beta_{6} \ln E C+u \\
\ln E E=C+\beta_{1} \ln G P+\beta_{2} \ln C L+\beta_{3} \ln L F+\beta_{4} \ln E R+\beta_{5} \ln I S+\beta_{6} E C+u
\end{gathered}
$$

(2) Analysis of empirical results

From the analysis results of Model 1, green technological innovation has no positive impact on economic growth. The main reason may be that enterprises, as the main body of technological innovation, face the requirements of government environmental regulations and have a crowding-out effect on the marketoriented innovation behavior of enterprises. Technological innovation has not translated into economic benefits. Capital investment has shown a trend of diminishing marginal returns, and economic growth is mainly due to environmental governance investment, labor investment and energy efficiency improvement. In the case of basically the same benefits, the cost of green technological innovation is higher than non-green technological innovation, so that its market competitiveness is lower than that of non-green technologies, and enterprises have insufficient motivation for green technological innovation. At the same time, the return on investment in technologyl innovation varies greatly, and the uncertainty of technological investment is also a major problem hindering innovation. From the perspective of the consumer market, green products often lack differences from other products. In particular, the green production process of many industrial products cannot be transformed into product advantages and competitive advantages, and consumers have insufficient recognition of green products.

Table1. Model estimation results

\begin{tabular}{lllll}
\hline variable & coefficient & \multicolumn{1}{c}{$\begin{array}{c}\text { Standard } \\
\text { deviation }\end{array}$} & T statistics & P value \\
\hline GP & -0.004 & 0.529 & -0.71 & 0.004 \\
CI & -0.108 & 1.589 & -5.26 & 0.013 \\
LF & 0.255 & 2.114 & 3.45 & 0.084 \\
ER & 0.155 & 0.857 & 1.81 & 0.167 \\
IS & -0.335 & 0.043 & -5.69 & 0.005 \\
EC & 0.039 & 2.850 & 0.19 & 0.062 \\
$\mathbf{C}$ & 0.504 & 4.207 & 0.39 & 0.024 \\
$\mathbf{R}^{\mathbf{2}}$ & 0.99 & $\mathrm{f}$ & 16.35 & \\
\hline
\end{tabular}

From the results of environmental efficiency regression, green technology has a positive effect on environmental improvement. The improvement of the ecological environment is mainly due to the adjustment of industrial structure and the improvement of energy consumption efficiency. Strict environmental regulations can add additional costs to companies, and companies have to adjust their development strategies and adopt pollution prevention and control technologies to respond to environmental regulations, thereby reducing environmental harm. Since pure environmental regulations generally lead to higher costs and a decline in manufacturing total factor productivity, environmental regulations need to leapfrog the level of technological innovation in order to truly promote the development of green industrial transformation. In addition, the application of technology may change the structure of production factors and production methods of enterprises, increase additional costs, and make enterprises lack the motivation for green technological innovation. Enterprises's green technology innovation is affected by multiple factors such as talents, capital, technology, data, and information. It is generally difficult for a single company to have the ability to integrate all the factors, which restrict the pace of corporate green technology innovation. 
Table 2 . Model estimation results

\begin{tabular}{lllll}
\hline variable & coefficient & \multicolumn{1}{c}{$\begin{array}{c}\text { Standard } \\
\text { deviation }\end{array}$} & T statistics & P value \\
\hline GP & 0.021 & 0.055 & 0.38 & 0.032 \\
CI & -0.167 & 0.098 & -1.70 & 0.087 \\
LF & -0.628 & 1.819 & -0.90 & 0.037 \\
ER & -0.071 & 0.091 & -0.78 & 0.294 \\
IS & 0.124 & 0.005 & 1.45 & 0.242 \\
EC & 0.249 & 0.309 & 1.45 & 0.142 \\
C & 0.652 & 20.253 & 1.02 & 0.383 \\
$\mathbf{R}^{2}$ & 0.939 & $\mathrm{f}$ & 17.56 & \\
\hline
\end{tabular}

\section{Conclusions and recommendations}

\section{1 conclusions}

Generally speaking, green technological innovation has not yet shown its role in promoting economic growth, but it has played a positive role in improving the environment. Enterprise green technology innovation is mainly affected by environmental regulations and lacks active innovation motivation. It can be seen that a market-oriented green technology innovation system has not yet been formed. In many cases, due to the spillover effect of knowledge, innovators engaged in R\&D cannot obtain the benefits of innovation results. The externalities of technological innovation may lead to a reduction in R\&D investment. Environmental regulations will squeeze out the spontaneous innovation funds of enterprises, and will weaken the incentives for technological innovation of individual enterprises. At the same time, specific environmental, resource issues and industrial structure will have specific requirements for green technology innovation. The effect of the green technology innovation policy is not satisfactory.

\section{2 recomendations}

Increase research and development supports for green technology innovation. Depending on Porter's hypothesis, the improvement of ecological efficiency depends on technological innovation induced by environmental regulations. Product innovation can improve product design level and quality by taking environmental factors into consideration, gaining market benefits and higher marginal benefits. Process innovation can not only reduce costs, but also improve resource utilization efficiency. It is necessary to strengthen the status of enterprises as the mainstay of green technology innovation and promote the concentration of innovative elements in enterprises. Invest more in green technology innovation support funds, and implement tax incentives and other policies for green technology innovation. Fully develop the compensation role of technological innovation and seek to eliminate the adverse effects of environmental regulations on enterprises.

Strengthen collaborative innovations of factors. Green technological innovation requires the investment of diverse resources and elements. The green technological innovation of enterprises under environmental regulations aims to reduce waste discharge and pollution and treatment technology. Green R\&D investment may crowd out the normal production activities of enterprises effect. It is necessary to strengthen the cooperative relationship between enterprises, universities, and scientific research institutions, and promote the production of enterprise products to meet market demand. Promote the integration of technologies in diverse industries and enable green technologies to play a major role in economic growth through dynamic feedback of technology applications.

Cultivate a green consumer market. Powered by market demand, strengthen green product innovation. Encourage green product innovation through market signals, instead of directly specifying pollution control standards, and help companies flexibly choose the most economical way to raise environmental problems. In order to enable the policy of conditional capitalization of $R \& D$ expenditures to be promoted in more enterprises, to more effectively encourage enterprises to carry out technological innovation, and to guide consumers to choose products with green labels, so that enterprises can obtain green product $\mathrm{R} \& \mathrm{D}$ and innovation compensation benefits. It is necessary to strengthen taxation management and encourage enterprises that conduct vigorous research and development to enjoy tax benefits. Guide clients to increase awareness of environmental protection and force companies to conduct research and development and application of green technologies.

Optimize the portfolio of policy tools. The inverted $\mathrm{U}$ relationship between environmental regulation and environmental efficiency indicates that reasonable environmental regulation is an effective method to achieve the maximum environmental efficiency. The effective combination of environmental policy and technology policy will enhance the effect of green technology innovation policy implementation. Government guidance is an important measure to promote enterprises to increase investment in innovation and improve their innovation capabilities. Incentive policies should be used to guide enterprises to play an active part in technological innovation, such as tax incentives, and promote cooperation between scientific research institutions and enterprises. Enterprises should be guided to abandon passive resistance-based environmental development strategies or relatively passive response strategies, consciously establish environmental protection awareness, and choose active green development strategies. 


\section{Acknowledgments}

The authors gratefully acknowledge the financial support from Hebei Social Science Fund Project: Research on the Path of Economic High-quality Growth in Hebei Province under the Constraint of Carbon Emissions (HB20GL013)

\section{References:}

1. Chen Xiao, Li Meiling, Zhang Zhuangzhuang. Environmental Regulation, Government Subsidies and Green Technology Innovation-An Empirical Study Based on the Mediation Effect Model[J]. Industrial Technology Economics, 2019,38(09): 1825

2. Zhou Jingmiao, Zhao Yuzhe, Wu Chunyou, et al. Research on the Choice of Oriented Technology Innovation under Green Growth[J]. Journal of Management Science, 2018,21(10): 61-73.

3. He Xiaogang. Energy constraints, green technology innovation and sustainable growth: theoretical models and empirical evidence[J]. Journal of Zhongnan University of Economics and Law, 2015(04): 30-38.

4. Wang Yurong. Comparative Research on the Green Technological Innovation Performance of Enterprises in Various Regions of my country [J]. Technoeconomics, 2012,31(10): 52-59.

5. Han Rumei, Liu Yanchun. Research on the evaluation of Green Technology Innovation Efficiency of Industrial Enterprises in my country[J]. Technoeconomics and Management Research, 2017(5): 53-57.

6. Luo Liangwen, Liang Shengrong. Green technology innovation efficiency and factor decomposition of China's provincial industrial enterprises[J]. China Population-Resources and Environment, 2016,26(09): 149-157. 